\title{
Aspectos socio-organizacionales y de gstión de Emprendimientos Cooperativos en Costa Rica
}

\section{Resumen}

El siguiente artículo explica los factores estratégicos (gestión ambiental, inclusividad, articulación institucional y productiva, alianzas estratégicas, innovación, sostenibilidad alimentaria, nuevos sectores económicos) referente a la organización y gestión de emprendimientos cooperativos costarricenses.

De esta forma se sistematiza la experiencia organizativa y de operación de los emprendimientos cooperativos y cooperativas seleccionadas, mediante la recuperación y valoración crítica de dichas experiencias para mejorar éstas y otras prácticas a partir de las enseñanzas que surjan de propio proceso y difundirlas a otros actores claves relacionados con el quehacer de dichas cooperativas.

Palabras Claves: Factores Estratégicos, Emprendimientos Cooperativos, Artículación Productiva, Gestión, Sostenibilidad

\begin{abstract}
Abstrac
The following article explains strategic factors related to the area of promotion (environmental management, inclusiveness, institutional articulation, productive coordination, strategic alliances, innovation, food sustainability, new economic sectors) concerning the organization and operation of the Costa Rican cooperative ventures.

Thus the organizational and operating selected cooperative ventures and cooperative experience is systematized through recovery and critical appraisal of these experiences to improve these and other practices from the lessons that emerge from the process itself and spread them to other stakeholders related to the activities of these cooperatives.
\end{abstract}

Keywords :Strategic Factors, Cooperative Emprendimnientos, Productive Chain, Management, Sustainability

Recebido: 29/11/2016 Aceito: 19/04/2017

Gustavo Hernández Castro ${ }^{1}$, Federico Li Bonilla ${ }^{2}$

${ }^{1}$ Escuela Ciencias de la Administración, Universidad Estatal a Distancia, Costa Rica, Licenciado en Estudios Latinoamericanos, Máster en Administración de empresa - ghernandezc@ uned.ac.cr - Apartado postal 167-2300

${ }^{2}$ Escuela Ciencias de la Administración, Universidad Estatal a Distancia, Costa Rica - fli@ uned.ac.cr 


\section{Introducción}

El presente artículo sistematiza la investigación realizada en ocho cooperativas en la cual existe una necesidad puntual de generar empleo productivo e ingresos para mejorar la calidad de vida de sus asociados y de las comunidades anfitrionas.

De estos emprendimietos cooperativos, cuatro se dedican mayoritariamente a la agricultura, dos a la industria y dos a actividades de servicios. El siguiente cuadro describe la ubicación geográfica, la actividad económica y el sector en la cual pertenecen:

\section{Cuadro 1 \\ Actividad económica y ubicación de las cooperativas}

\begin{tabular}{|c|c|c|c|}
\hline ACTIVIDAD & SECTOR & UBICACION & $\begin{array}{c}\text { PROVINCI } \\
\text { A }\end{array}$ \\
\hline Call Center & Servicios & Urbana & San José \\
\hline Crianza pollo & Agricultura & \multirow{7}{*}{ Rural } & Alajuela \\
\hline $\begin{array}{l}\text { Producción de } \\
\text { lácteos }\end{array}$ & Agricultura & & Heredia \\
\hline $\begin{array}{l}\text { Jabón } \\
\text { champú }\end{array}$ & Industria & & Heredia \\
\hline Papaya & Agricultura & & Puntarenas \\
\hline Banano dátil & Agricultura & & Limón \\
\hline Turismo & Servicios & & Puntarenas \\
\hline $\begin{array}{ll}\begin{array}{l}\text { Pulpa } \\
\text { guayaba }\end{array} & \text { de } \\
\end{array}$ & Industria & & Cartago \\
\hline
\end{tabular}

Fuente: Federico Li y Gustavo Hernández (2015)

Solamente una de las cooperativas está ubicada en la zona urbana, las restantes son emprendimientos rurales. La única cooperativa urbana tiene características muy especiales al estar constituida por personas con discapacidad y dedicarse a ofrecer servicios de atención de llamadas telefónicas (call center) al Instituto Costarricense de Electricidad (ICE). Por otro lado, cuatro de las cooperativas se dedican a actividades agrícolas de pequeña escala, y sus asociados fundadores se dedicaban antes de que se constituyeran en cooperativas, a actividades agrícolas en menor escala (subsistencia).

Por las condiciones indicadas se puede concluir, de manera generalizada, que la idea de constituirse en cooperativa fue con la finalidad de asociarse o unir esfuerzos en procura de convertirse en propietarios bajo la figura del cooperativismo. Con ello se aprovechan las ventajas que la legislación costarricense ofrece al sector. Asimismo, con ello, se da un paso importante: pasar de condiciones de pobreza en la informalidad a vivir decentemente en la formalidad.

Un vistazo a las actividades incluidas en el cuadro 1, muestra que con la salvedad de emprendimiento dedicado al Call Center, las acciones a que se dedicaban los asociados de los otras cooperativas son propias de gestiones de baja productividad en sus respectivas localidades, por ejemplo la crianza de pollo, recolección de guayaba y de banano dátil son actividades de subsistencia que si acaso poseen un mercado formal donde transar los excedentes.

El emprendimiento dedicado al turismo, surgió del ingreso de turistas a una zona única por su belleza y por la existencia del Parque Nacional Corcovado en el Cantón de Osa, provincia de Puntarenas, que también en sus inicios, fueron actividades marginales, y que en el presente sufren de falta de mercado con la caída del turismo extranjero merced a la crisis financiera mundial asotada en el 2008. (Hernández, 2013)

El grupo de mujeres empresarias productoras de jabón y champú, tiene su génesis después del terremoto de Cinchona, el 8 de enero de 2009 (provincia de Heredia) y merced a la condición crítica en que 
quedó la zona (desempleo, pobreza, delincuencia y desamparo gubernamental) y aunado a la experiencia en fabricación de jabón y champú de una de las asociadas, se decidió afiliarse a esta cooperativa, dedicada al café, consolidada en la zona. (Hernández, 2015)

La condición de ruralidad es otro agravante toda vez que los mayores niveles de pobreza se registran en las zonas rurales del país. En buena parte ello obedece al abandono y escaso alcance de las politicas públicas que se traducen en malas carreteras y rutas de acceso, puentes, entre otros. La inversión social es igualmente escasa con pocas escuelas y servicios de salud. En estas condiciones las posibilidades de que la empresa privada se establezca en estas zonas son muy bajas, así como las opciones de ofrecer empleo productivo (MIDEPLAN, 2014).

\section{Metodología}

Esta investigación es de corte mixta; desde un paradigma interpretativo, este estudio recoge y analiza las posturas de los emprendedores, agentes intrainstitucionales y sujetos de información de las comunidades anfitrionas, en la cuales, se contextulizan las coopoerativas abordadas. (Hernández, Fernández y Baptista 2012)

Durante la etapa de la recolección de la información se combinaron instrumentos del enfoque cualitativo y cuantitativo, como lo son: cuadros estadísticos, cuestionarios, entrevistas en profundidad, observación participativa y grupos focales, lo cual ha permitido enmarcar el proceso dentro del enfoque mixto.

Es menester aclarar que a solictud de los distintos representantes legales de las cooperativas investigadas, se omite el nombre jurídico de estas y, solamente se menciona la actividad económica que realiza cada emprendimiento cooperativo.

Asimismo, los investigadores dejan abierta la posibilidad a los interesados en la temática, de solicitar información de la base de datos disponible, que sustentan las variables estadísticas y matemáticas que alimentaron el desarrollo y las posteriores conclusiones que arrojó la pesquisa.

\section{Análisis de variables}

Se procedió al análisis de las variables con el propósito e identificar las subyacentes, o bien, que explicaran la configuración de correlaciones dentro de las variables observadas. Estas explican y tipifican el modelo de organización y operación de los emprendimientos cooperativos en siete componentes, a saber:

- Factores económicos

- Valores y principios cooperativos

- Externalidades cooperativas positivas

- Responsabilidad social cooperativa

- Creación y organización de cooperativas

- Toma de decisiones cooperativas

Es importante resaltar el orden de jerarquía que se da con el análisis multivariado de factores. Según Li (2013) este método que escruta el factor que manifieste la cantidad principal y de mayor significancia sobre la varianza en la matriz. De cada factor se obtiene una valoración propia asociada, que corresponde a una varianza. Esta varianza es una comunalidad, es decir, una cuantía de varianza de la pregunta analizada con las demás preguntas sometidas a investigación, (Hillier y Hillier, 2008)

Con este análisis factorial sin rotar, la matriz obtenida brinda las contribuciones de las preguntas o variables que dan una fuerte correlación al componente o constructo, es decir, la vinculación entre las preguntas y el componente o factor obtenido. Una característica muy importante cuando se realiza un análisis factorial sin rotar, es la alta relación de variables dentro del componente propuesto, (Hernández, Li y Cordero, 2016).

El análisis de los componentes principales es la transformación lineal en un sistema diferente de coordenadas al agregado de información para la cual la varianza de mayor importancia se da en el primer pilar, conocido como el principal componente o constructo, siendo sus variables las originales e independientes entre sí; el cual explica en un determinado porcentaje el modelo propuesto.

El análisis factorial o reducción de factores, se obtiene por ciento de la varianza total. De tal manera que el porcentaje obtenido brinda un valor el cual determina si es el análisis es válido o no. Se consideran válidos los resultados si los factores explican al menos $95 \%$ en las ciencias naturales; para el caso de esta investigación y de las ciencias sociales es frecuente un resultado del 60 al $65 \%$ del total de la varianza. (Kline, 1998)

En cuanto a la interpretación de los resultados en cada factor, se debe tener en cuenta que el mínimo requerido es de $\pm 0,30$, de forma tal que valores de 
$\pm 0,40$ son importantes a considerar y valores superiores a $\pm 0,50$ son significativos. Para el análisis de esta investigación se consideró, como parámetro mínimo para la reducción de factores y tal como se indicó en el análisis de reducción de factores, el límite igual o superior a 0,50 de los diferentes factores que arrojara el modelo multifactorial. Es así como los resultados obtenidos superiores a 0,50 en su valor absoluto, se consideran variables de mucho peso e importantes en la determinación del modelo propuesto. (Byrne, 2011)

Adicionalmente, se aplicaron metodologías interactivas grupales como talleres in situ. En ellos se contó con la participación de sujetos claves que conocieran a fondo la cooperativa, desde sus mismos orígenes, que identificaran los problemas sucedidos en el pasado, reconioceran las dificultades actuales y las perspectivas futuras de cada emprendimiento.

Se validaron los instrumentos de recolección de información (encuesta de sistematización de experiencias) así como su aplicación. Para lo anterior se acordó realizar talleres individuales en cada cooperativa y un taller final con la presencia de las ocho cooperativas para presentar los resultados y las lecciones aprendidas en cada una de estas organizaciones. (Li, 2013)

Adicionalmente se establecieron los siguientes lineamientos metodológicos:

1. Explicación de objetivos y las técnicas paticipativas de los talleres a realizar (preguntas e inquietudes de participantes).

2. Conformación de grupos para la elaboración de los insumos grupales según los objetivos plantaedos.

3. Elaboración de un documento de la situación actual y perspectivas y el levantamiento de información, medinate la técnica FODA.

4. Se aplicaron dos preguntas para desorrollar la técnica participativa del sociograma:

- ¿Cuando tienen problemas en la cooperativa, a quienes o a qué instancias acuden?

- ¿Quién es el líder de su cooperativa?

En la mayoría de las cooperativas analizadas siempre existió una persona que de alguna manera $\mathrm{u}$ otra motivó a otros a conformar un grupo y fundar un emprendimiento productivo amparado a los beneficios del cooperativismo. Es decir, el apoyo brindado por el cooperativismo y sus ventajas se constituyeron en el eje central de la creación de cada uno de los emprendimientos cooperativos.

Las ventajas de ser cooperativa se pueden resumir en fácil acceso al apoyo estatal, exoneraciones de impuestos, apoyo financiero del Instituto Nacional de Fomento Cooperativo (INFOCOOP), capacitación y entrenamiento por parte del Instituo Nacional de Aprendizaje (INA) y las universidades estatales, entre otros.

Cuadro 2

Gestores e idea de cooperativas

\begin{tabular}{|c|c|c|c|}
\hline Actividad & $\begin{array}{c}\text { Gestores } \\
\text { (iniclales de } \\
\text { los nombres) }\end{array}$ & Posición jerárquica & Idea \\
\hline Crianza de pollos & YR y FP & Presidenta & Planta de destace \\
\hline Call Center & ES & Gerente & Call Center \\
\hline Productos lácteos & AT & Gerente & Procesamiento de queso \\
\hline Papaya & VC y BR & Gerente y presidente & Exportación de papaya \\
\hline Banano dátil & RL & Gerente & $\begin{array}{c}\text { Exportación de banano } \\
\text { dátil }\end{array}$ \\
\hline Turismo & $\mathrm{EE}$ & Gerente & Comercializadora turística \\
\hline Jabón y champú & GI & Líder en Cinchona & Champú y jabones \\
\hline Pulpa de guayaba & $\mathrm{AM}$ y $\mathrm{AM}$ & $\begin{array}{l}\text { Gerente y Presidente, ambos médicos de } \\
\text { Centros de Educación y Nutrición y de } \\
\text { Centros Infantiles de Atención Integral } \\
\text { (Cen-Cinai) en Grano de Oro, Chirripó. }\end{array}$ & $\begin{array}{c}\text { Industria de pulpa } \\
\text { guayaba }\end{array}$ \\
\hline
\end{tabular}

Fuente: Federico Li y Gustavo Hernández (2015) 
Los gestores de las diferentes ideas que originaron las cooperativas estudiadas normalmente asumen las posiciones de liderazgo o gerenciales en las cooperativas, ello coincide con las respuestas encontradas en los sociogramas aplicados. En algunos casos, los gestores de las cooperativas son personas conocedoras de la actividad como el grupo de mujeres que producen jabón y champú, turismo, papaya, y banano dáctil. En otras instancias estos gestores desconocen sobre la nueva actividad cual es el caso de las que se dedican a procesar pulpa de guayaba y a la gestión del Call Center. En el caso del emprendimiento dedicao a la producción de lácteos el gestor es un estudiante de la carrera de Planificación y Promoción Social de una universidad pública, quién llegó a la zona a realizar su trabajo final de graduación.

En algunos casos los gestores son profesionales o personas con altos niveles de estudio que han venido a asesorar a las empresas o que organizan a un grupo para convertir una idea en realidad. Ejemplos de ello son el emprendimiento de lácteos quienes recibieron asesoría en administración de un estudiante universitario, que a la postre se convirtió en su gerente; algo similar ocurrió con la coperativa dedicada al banano dátil, cuyo gerente actual, es historiador y profesor universitario; en la cooperativa dedica a la pulpa de guayaba, sus gestores son médicos que visualizaron en la industrialización de la guayaba una salida de la pobreza; por su parte, la cooperativa dedicada a la producción de papaya, cuyo actual gerente fue un diplomático costarricense en Panamá y se constituyó en líder de la cooperativa, a la par de un excelente agricultor de la zona. Por otro lado, el Call Center, se instituyó gracias a instancias de un profesor pensionado que creyó en la potencialidad de las personas con discapacidad (Infante, 2012).

\section{Origen De Los Emprendimnientos Cooperativos (Ideas)}

El origen de los emprendiientos está íntimamente relacionado con los gestores mencionados en el Cuadro 2. Las motivaciones son diversas y vinculadas desde luego con la zona geográfica y el entorno particular de cada cooperativa. Por ejemplo, la fruta de la guayaba abunda en Chirripó entonces ¿por qué no procesarla? Así nace la idea de crear la cooperativa. Lo mismo se aplica a la producción de leche y del emprendimiento de la producción de papaya y los servicios de turismo. Es decir, debe existir una aparente ventaja comparativa en bienes abundantes en la región que se puede explotar agragándole valor o comercializándolos de manera asociativa y para ello nada mejor que una cooperativa. (Porter, 2009)

Un caso especial es el emprendimiento de Call Center. La idea surge en un equipo deportivo en Centro Nacional de rehabilitación (CENARE) cuyos integrantes se cuestionan ¿qué harán luego de salir del tratamiento médico?, ¿las desventajas de su discapacidad los condenarían a una vida de dependencia? o ¿podrá ser aprovechada en sus propios beneficios gracias a la Ley 7600 ? Estas personas optaron por la segunda opción y transformaron una debilidad en fortaleza que incluso fue reforzada por las ventajas derivadas del cooperativismo. (Griffin, 2011)

El caso de la cooperativa dedicada a la producción de papaya es enriquecedor. El precio de esta fruta, al momento de hacer la investigación, estaba estipulado en tres mil colones el kilogramo $(\$ 5,56)$ en el contexto de que los mercados mundiales pagan mejores precios que los locales y con el conocimiento de que la papaya producida en el Pacífico Central de Costa Rica es de primera calidad (o calidad de exportación), se han organizado para sacar provecho del precio y de la calidad, conquistando el mercado de Canadá, donde no hay problemas de certificación de ingreso. A la fecha han vendido exitosamente en ese mercado.

En cuanto a la cooperativa dedicada a la crianza de pollo, causa extrañeza el caso de cómo deciden sus gestoras instalar una planta procesadora de pollo en un lugar donde las ventajas comparativas están localizadas en el procesamiento de frutas, que además de su abundancia, como insumos, son más amigables con el medio ambiente que el destace de pollo, surge la pregunta: ¿qué hace que un ejecutivo o líder sea eficaz? (Drucker, 2004)

\section{Perfil del grupo}

De lo expuesto se puede afirmar que la idea de conformarse en cooperativa surge de la necesidad de aprovechar de mejor manera los recursos abundantes (con ventajas comparativas aparentes) de la zona combinado con la experiencia de los 
asociados con el objetivo de generar empleo productivo y salir de la pobreza. (Li, 1989,2013)

En síntesis, algunos detonantes en la fundación de las cooperativas son:

Pobreza: esta variable fue reiteradamente mencionada como central en la decisión de crear la cooperativa. Es decir, las personas que fundaron la cooperativa en su mayoría estaban en condición de pobreza.
Desempleo: la mayor parte de las personas citaron que al momento de su creación, no tenían nada qué hacer por cuanto las opciones de encontrar empleo en las zonas rurales alejadas del centro son ínfimas.

> Bajo nivel de educación y capacitación: la encuesta y estudios de apoyo del INFOCOOP registraron al bajo nivel educativo como una enorme desventaja en las cooperativas estudiadas. El gráfico 1 ilustra el fenómeno.

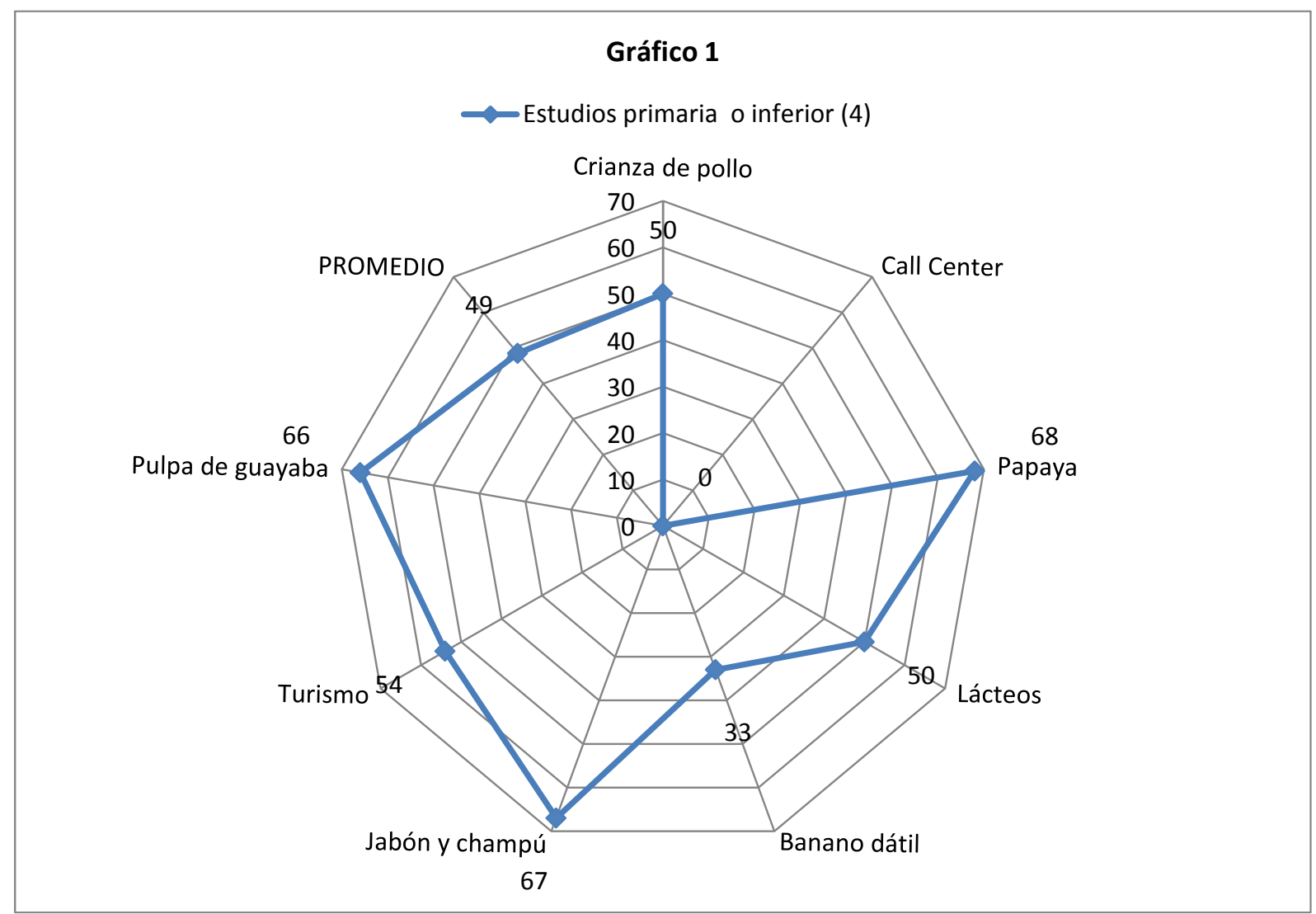

Fuente: Fedrico Li y Gustavo Hernández (2015) con base en datos de la encuesta y del INFOCCOP.

En el gráfico 1 se observa que la cooperativa dedicada al Call Center es la que posee un mayor nivel educativo al tener un $100 \%$ de sus asociados con educación primaria terminada, lo cual es obvio dada las funciones que realiza que requieren de poseer un adecuado nivel educativo. En el otro extremo, la mayoría de los emprendimientos, muestran porcentajes de alrededor del $50 \%$ con solo educación primaria concluida o inferior a la primaria.

En términos generales las cooperativas analizadas, se pueden categorizar como trabajadores independientes, desempleados o amas de casa en busca de opciones de trabajo o personas deseosas de crear su propio emprendimiento en zonas de alta pobreza donde las oportunidades son escasas o inexistentes. (Hernández, 2014)

\section{Áreas o temas estratégicos en la que se pueden categorizar las cooperativas}

Las cooperativas incluidas en la muestra son de muy diversas calidades, según se muestran en el Cuadro 1. Hay emprendimientos agrícolas como de servicios, algunas son microemprendimientos, otras son de mayor tamaño. Por ejemplo, la cooperativadedicada al Call Center posee más de cuarenta asociados, en tanto, que la dedicada a la cranza de pollos, no llegan a la docena de asociadas. 
Algunas poseen una amplia cobertura geográfica como la cooperativa dedicada a lácteos y al apulpa de guayaba, a diferencia de otras, donde la cobertura geográfica en irrelevante como la que presta servicio de Call Center. Esta cooperativa es estratégica al apoyar a un segmento poblacional desprotegido y frágil como las personas con discapacidad, y en la cual, para ngresar como asociado, este es un requisito esencial. La capacidad de conseguir trabajo para la población discapacitada es muy baja por lo que una cooperativa que los apalanque es una idea singular y de su éxito podría depender la incorporación de un amplio sector poblacional al mercado de trabajo.

Otra área estratégica que conviene mencionar, es el tema del desempleo indígena, que fue originalmente el enfoque del empredimiento dedicado a la pulpa de guayaba. Al promoverse el proyecto en Chirripó, la zona densamente poblada por la etnia indígena, se previó que el proyecto podría ser clave para proporcionar empleo e ingresos, sacando así a muchas familas de la pobreza. La posibilidad de producir a bajos costos gracias a la abundancia de guayaba en la zona parecía muy viable, lamentablemente un error de predicción en los precios de mercado y su tamaño dio al traste con el proyecto. Al reducirse la posibilidad de su viabilidad financiera el interés de los 110 asociados que originalmente constituyeron la cooperativa, desapareció, a tal grado que hay menos de diez asociados activos.

\section{Etapas de desarrollo de los emprendimientos estudiados}

Algunos proyectos no han logrado sobrepasar su etapa de infancia como se desprende de las narraciones y las técnicas participativas aplicadas por los participantes en los talleres.

- Emprendimiento crianza de pollo: en la dinámica de grupo, se solicitó a los participantes realizar un dibujo relacionado del emprendimiento con las fases de vida de unas personas (niño, adolescente y adulto) estos dibujaron niños que no superaron la etapa de la adolescencia.

- Emprendimiento pulpa de guayaba: se dibujó a una planta en germinación que nunca logró crecer. Ello es producto de obstáculos en la gestación de las empresas; por ejemplo, esta cooperativa, como la de de crianza de pollo, están casi extintas, si no cambian de rumbo, terminaran desapareciendo.

- Emprendimiento del grupo de mujeres empresarias que se asociaron a la cooperativa de producción de jabón y champú, deberán superar la falta de permisos del Ministerio de Salud y su problemática relación empresarial con la cooperativa madre.

- Otros emprendimientos que está en vías de consolidación es la de lácteos que a pesar de que necesita una planta procesadora, sus asociados en su mayoría están activos y han participado en ferias para la promoción y venta del queso. Tienen un liderazgo positivo y se espera que tengan un buen porvenir.

- El emprendimiento de turismo pasa en la actualidad por problemas de mercado ante la caída del turismo mundial, sin que se prevea un descalabro total. El apoyo de las fundaciones Neotrópica y Corcovado y las bellezas naturales de la Península de OSA los sostiene $\mathrm{y}$, posiblemente, se recuperarán junto con la economía norteamericana que a junio 2014 muestra señales de crecimiento.

Las tres cooperativas que aparentan estar en buenas condiciones de crecer y prosperar en el futuro cercano son la dedicada a la producción de papaya, que exporta con éxito papaya a Canadá; el emprendimiento dedicado al banano dátil que ha finiquitado buenos contratos futuros con exportadores de banano como Bananera Acón y Chiquita. Finalmente, la cooperativa que presta servicio de Call Center, es quizás la cooperativa con mejores perspectivas futuras de las analizadas, que se ha trazado un plan de crecimiento vigoroso y viable, en la cual su nuevo gerente ha jugado un papel preponderante. $\mathrm{Su}$ aporte debe hacerse extensivo a la función social que dicha empresa ha realizado con un grupo socialmente marginado. Es ejemplo digno de replicación.

Los problemas que han surgido en la génesis de las cooperativas estudiadas tienen que ver fundamentalmente con las altas expectativas y sobre el optimismo con que nacen. A veces es mejor ser un poco menos optimista y bajar el nivel de expectativa para que el emprendimiento sea un éxito. 
Cuadro 3

Problemas y necesidades claves

\begin{tabular}{|c|c|c|c|}
\hline Actividad & Necesidad inmediatas & Propósito & Situación actual \\
\hline Crianza de pollo & $\begin{array}{c}\text { Donación de terreno } \\
\text { para planta de destace }\end{array}$ & Destace de pollo & $\begin{array}{c}\text { Esperaban donación de } \\
\text { Instituto de Desarrollo Rural } \\
\text { (INDER). Donación rechazada }\end{array}$ \\
\hline Call Center & Nuevo edificio & $\begin{array}{c}\text { Acondicionar a nuevas demandas y } \\
\text { no alquilar }\end{array}$ & $\begin{array}{c}\text { Esperan donación o venta de } \\
\text { lote }\end{array}$ \\
\hline Lácteos & Terreno & Producción de queso & $\begin{array}{c}\text { Esperan resolución de INDER } \\
\text { para arrendar una propiedad }\end{array}$ \\
\hline Papaya & Finca y terreno & $\begin{array}{c}\text { Procesamiento, empaque de papaya y } \\
\text { rotación de cultivos aś como ampliar } \\
\text { producción }\end{array}$ & $\begin{array}{c}\text { A la espera de respuesta de } \\
\text { INDER para arrendar finca }\end{array}$ \\
\hline Banano dátil & Terreno & $\begin{array}{c}\text { Procesamiento y empaque de banano } \\
\text { dátil }\end{array}$ & En busca de terreno \\
\hline Turismo & Local propio & $\begin{array}{c}\text { Oficinas propias para reuniones y } \\
\text { venta de paquetes }\end{array}$ & En busca de recursos \\
\hline Jabón y champú & Local para producir & En stand by & Espera de permisos de salud. \\
\hline Pulpa de guayaba & Local & Procesamiento de maracuya o café & $\begin{array}{c}\text { A nivel de idea. Pulpa de } \\
\text { guayaba no es viable }\end{array}$ \\
\hline
\end{tabular}

Fuente: Fedrico Li y Gustavo Hernández (2015)

Es destacable que la dependencia de donaciones $\mathrm{o}$ arrendamientos en condiciones favorables del INDER, o la falta de permisos de operación por parte del Ministerio de Salud no deja de ser un problema para varias de ellas. Por ejemplo, la coperativa dedicada a la crianza de pollo, no ha podido superar la negación del permiso de las autoridades sanitarias, así como el grupo de mujeres de que producen jabon y champú. Es decir, estas dos empresas son tan frágiles desde sus inicios que al negárseles un permiso se termina la cooperativa.

\section{Acompañamiento del INFOCCOP}

La labor de acompañamiento de INFOCOOP ha sido reconocida por las cooperativas estudiadas.

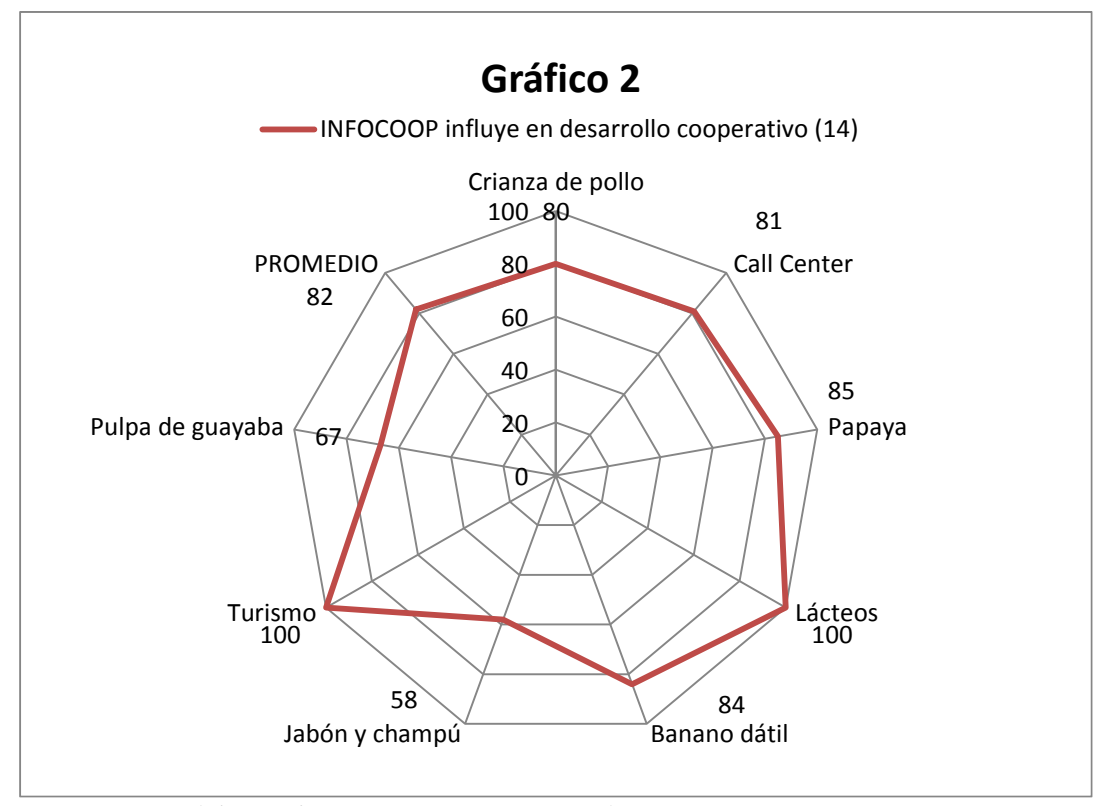

Fuente: Fedrico Li y Gustavo Hernández (2015) 
Del gráfico 2, se desprende que con la salvedad de las asociadas a al emprendimiento dedicado a la producción de jabón y champú, 58\% opinan a favor del aporte positivo de INFOCOOP, las restantes apoyan la labor del instituto en la creción y consolidación de las cooperativas del país. Sin duda esta respuesta puede estar vinculada con las expectativas y la realidad. A menudo un fracaso se asocia con falta de apoyo cuando la realidad del fracaso radica en otro lado como falta de mercado o de permisos sanitarios.
Las ocho cooperativas incluidas en la investigación recibieron suficiente asesoramiento por parte del INFOCOOP, tanto por parte del Departamento de Promoción como de otras instancias del Instituto.

El Gráfico 3, refleja la opinión sobre la influencia positiva del INFOCCOP en desarrollo de la cooperativa. Es decir si ha habido satisfacción con el apoyo brindado.

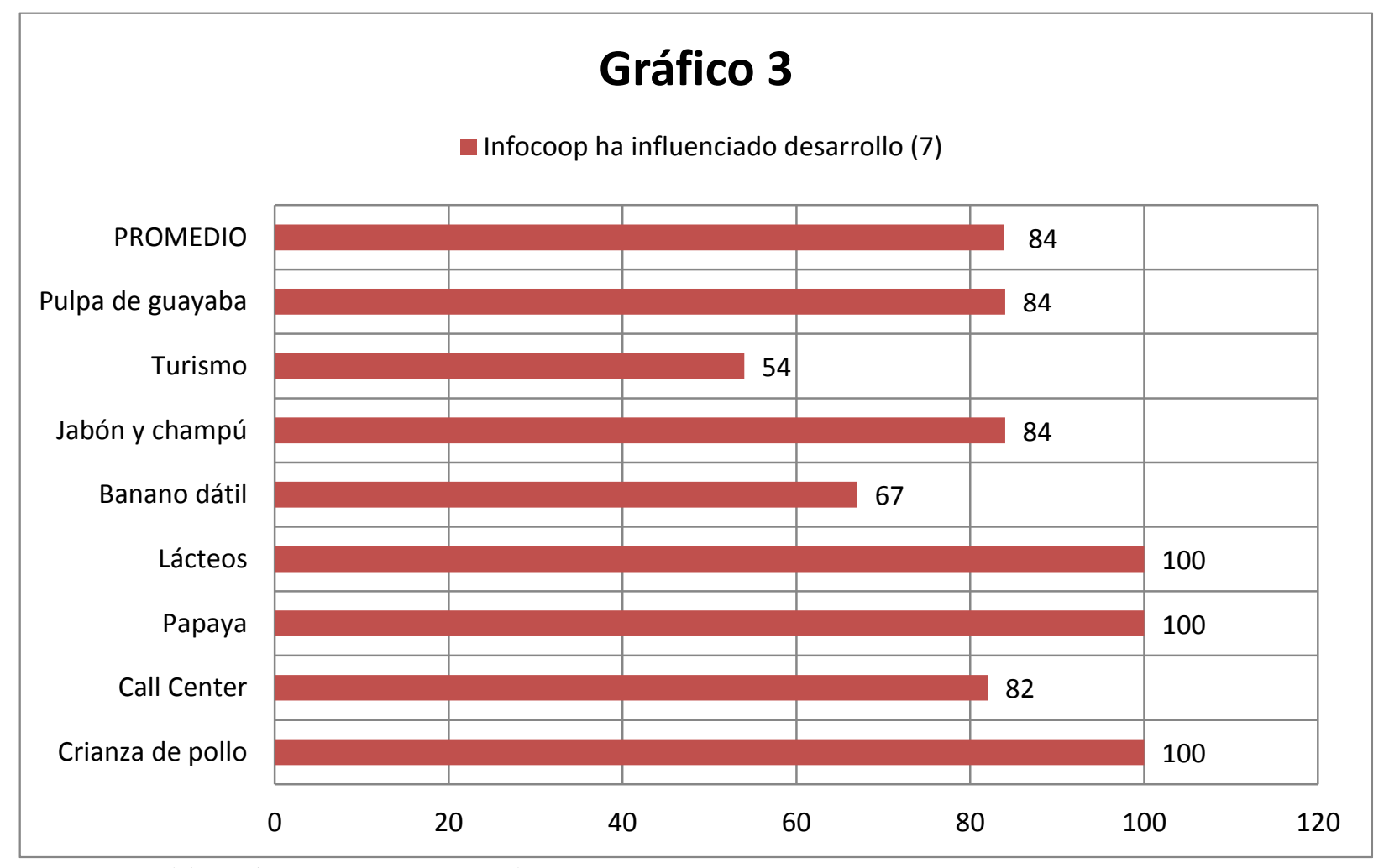

Fuente: Fedrico Li y Gustavo Hernández (2015)

El promedio de respuestas afirmativas fue de 84, dándose las respuestas más bajas en la cooperativa dedicada al turismo con un $54 \%$ y en el emprendimiento de producción de banano dátil, del $67 \%$. Pero de cualquier manera, existe una mayoría de respuestas afirmativas. (INFOCCOP, 2014)

\section{Perfil de entrada y salida del grupo según etapa}

El perfil de entrada de las cooperativas analizadas se ubica en básico. Es decir, no estaban conformadas en algún tipo de organización productiva. Eran más bien productores individuales atomizados y dispersos que de alguna manera u otra se unieron y organizaron en cooperativa. Ya se han explicado las muy diversas circunstancias en que se dieron estos encuentros.

Lo cierto del caso es que la forma de organización fue de cooperativa basada en las ventajas legales que el cooperativismo ofrece en Costa Rica. 
Cuadro 4

Etapas de las cooperativas

\begin{tabular}{|c|c|c|c|}
\hline \multirow{2}{*}{ Cooperativa } & Etapa de organización & $\begin{array}{c}\text { Etapa de } \\
\text { Producción } \\
\text { (I) }\end{array}$ & $\begin{array}{c}\text { Etapa de mercado } \\
\text { (2) }\end{array}$ \\
\hline Crianza de pollo & I & $\mathrm{I}$ & $\mathrm{I}$ \\
\hline Call Center & \multirow{3}{*}{$\mathrm{CO}$} & $\mathrm{CP}$ & $\mathrm{CM}$ \\
\hline Lácteos & & $\mathrm{I}$ & $\mathrm{I}$ \\
\hline Papaya & & $\mathrm{CP}$ & $\mathrm{CM}$ \\
\cline { 1 - 1 } banano dátil & & & $\mathrm{I}$ \\
\hline Turismo & & $\mathrm{I}$ & \\
\hline Jabon y champú & $\mathrm{I}$ & $\mathrm{I}$ & \\
\hline Pulpa de guayaba & $\mathrm{I}$ & & \\
\hline
\end{tabular}

Fuente: Fedrico Li y Gustavo Hernández (2015)

El Cuadro 4, refleja que tres de las cooperativas apenas han logrado alcanzar incipientemente algunas etapas operativas como la organización y la producción. Es decir, lograron una organización incipiente (I) para conseguir apoyos diversos pero insuficientes, y lograron producir, pero no de modo sostenible (crianza de pollo, jabón y champú y pulpa de guayaba). el emprendimiento de lácteos., logró superar la organización, pero su producción es aún incipiente. Los tres restantes han logrado ingresar a la etapa 2 y 3 que es la consolidación de producción (CP), consolidación de organizativa (CO) y de consolidación de mercados (COM). Ellas son la cooperativa dedica a la producción de papaya, el emprendimiento de Call Center y la dedicada a la producción de banano dátil.

Las tres cooperativas con peor desempeño no lograron pasar solventemente a una segunda etapa y menos a la tercera. Por ejemplo, la dedicada a la crianza de pollo que recibió subsidios en dinero y especie (donación de pollitos), pero que está a punto de disolución real como cooperativa ya que producen pollo y otras cosas independientemente. Lo mismo ocurre con la cooperativa dedicada a la producción de pulpa de papaya, que reempacó la planta procesodora de jalea de guayaba.

De modo similar el grupo de mujeres empresarias de jabón y champú están paralizadas por falta del permiso sanitario, lo que la mantiene en virtual interrupción y hace que cada una se dedique a lo propio.

\section{Cohesión del grupo y trabajo en equipo}

La cohesión de grupo es una de las características más destacables en el estudio. Al fin y al cabo esa es una de las facetas más importantes del cooperativismo. La encuesta refleja que esta variable es central y preponderante en la muestra analizada. Por ejemplo, la pregunta sobre si existe igualdad de oportunidades, la respuesta fue afirmativa:

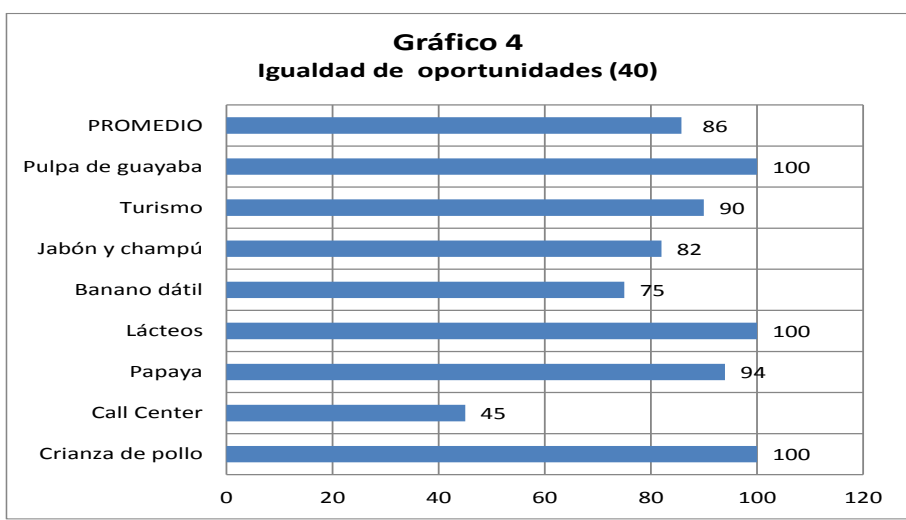

Fuente: Fedrico Li y Gustavo Hernández (2015)

El promedio de las respuestas afirmativas fue $86 \%$. Solamente enl emprendimiento dedicado al Call Center, mencionó afirmativamente en $45 \%$ de las veces. Ello quizá obedece a que la cooperativa trabaja exclusivamente con personas con discapacidad (no admite a personas sin discapacidad). 
Referente al trabajo en equipo, el gráfico 5, muestra la percepción sobre este:

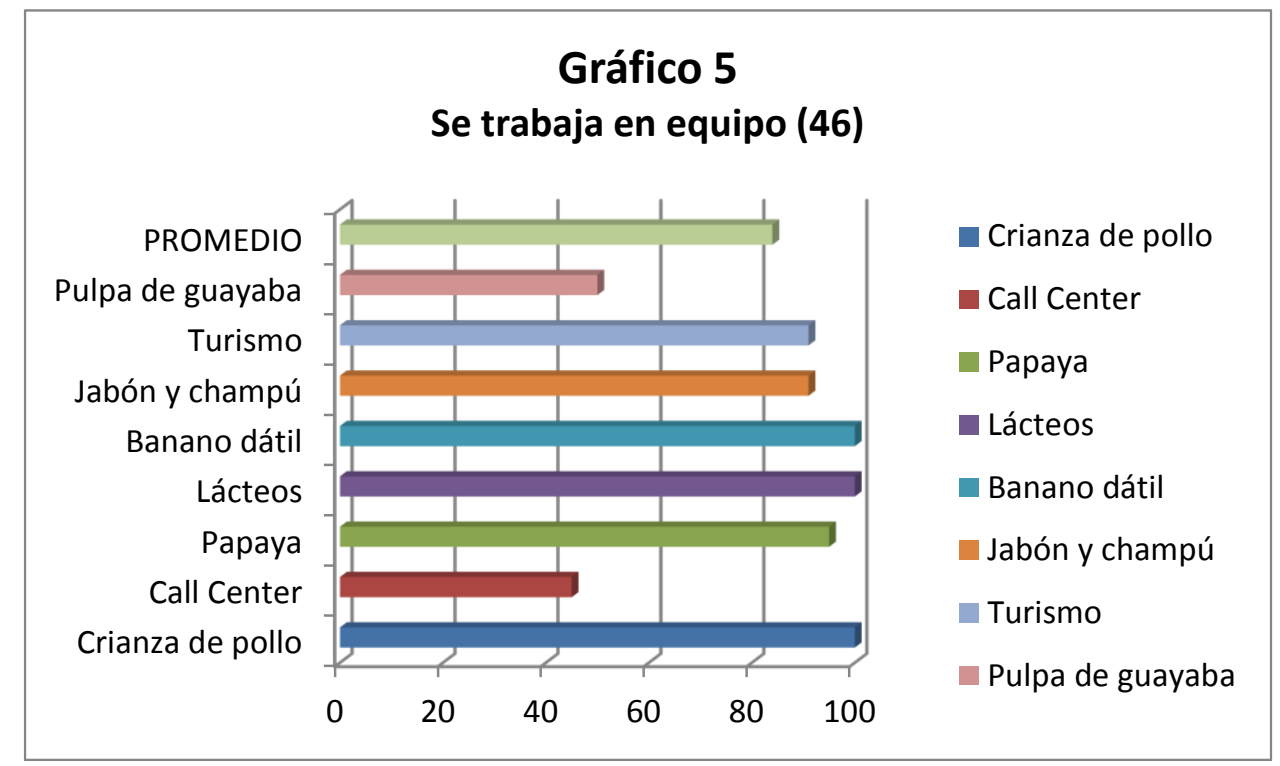

Fuente: Federico Li y Gustavo Hernández (2015)

El gráfico 5 tiene un promedio muy similar al gráfico 4 (84\%) y existe coincidencia en el sentido de que emprendimiento dedicado al Call Center. es la cooperativa que muestra los niveles más bajos de igualdad de oportunidades y en trabajo en equipo $(45 \%)$.

En términos generales existe una elevada igualdad de oportunidades así como de trabajo en equipo como corresponde a asociaciones cooperativas.

\section{Identificación de liderazgos}

Aunque las personas que ejercen el liderazgo no necesariamente debieran recaer en la gerencia o en la presidencia, en las cooperativas analizadas así pareciera ser. Los líderes han sido las personas que idearon y lideraron las cooperativas desde sus inicios, así las personas que gestaron y conformaron todos los procesos de las cooperativas son hoy sus líderes.

Las excepciones del caso son el emprendimiento de Call Center, en la cual dos de sus actuales líderes no son fundadores: actual Gerente y su asistente de gerencia, que si bien ha sido asociada desde sus inicios, no ocupaba esa posición. El otro caso de excepción es la cooperativa de crianza de pollo. donde su presidenta original, según manifestaron las asociadas, abusó de su poder y tuvo que abandonar dicho puesto. En la actualidad existe otra lider que es su gerente.

\section{El sociograma de liderazgo}

En cada una de las cooperativas y como se consigna en los informes parciales, se aplicó un instrumento denominado sociograma. En este se hacen dos preguntas: a quién recurre cuando tiene un problema (liderazgo real) y quién es el líder en su cooperativa (liderazgo formal). Los resultados de la encuesta, según consta en los informes parciales de cada cooperativa, confirma lo anteriormente expuesto: el liderazgo lo ostentan los actuales presidentes o gerentes.

Para llegar a estas conclusiones se utilizaron las preguntas:

1. ¿Cuándo en la cooperativa hay un problema yo recurro a...?

2. ¿Yo creo que el/la líder de la cooperativa?

De lo cual se realizó un socio grama o flujograma de relación de liderazgo-poder, la figura 6 , muestra los resultados: 


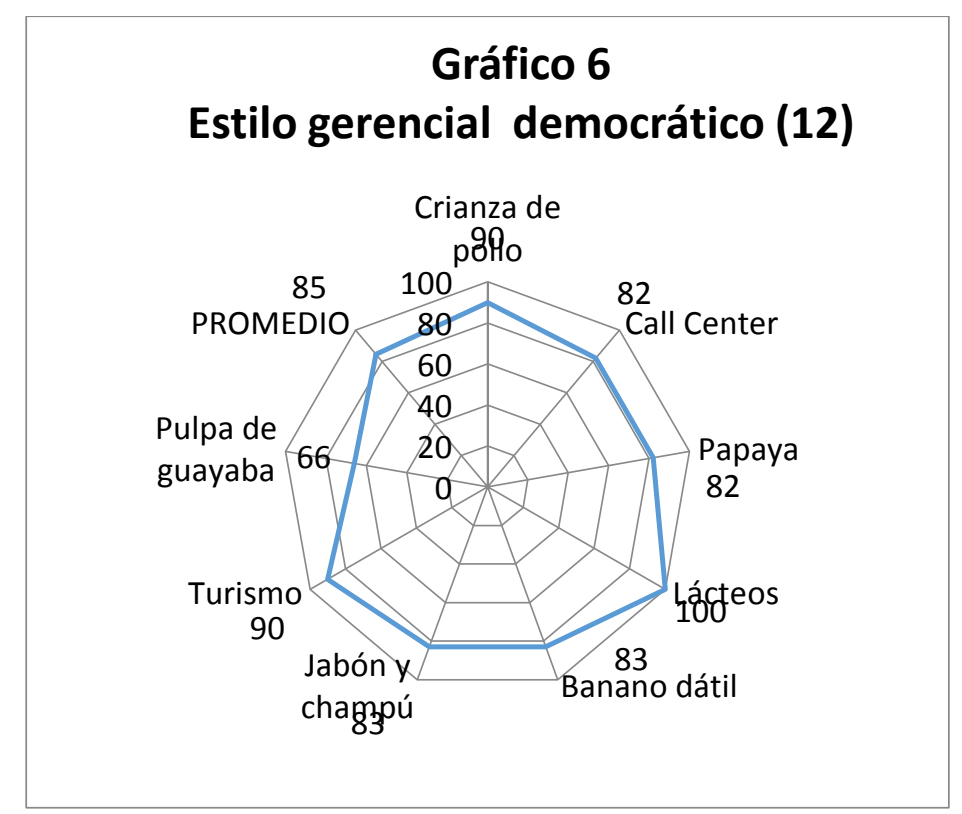

Fuente: Federico Li y Gustavo Hernández (2015)

En general hay diversos liderazgos que responden a distintas habilidades y a estilos gerenciales establecidos. Además de la existencia de una coherencia líder-cargo en la cooperativa. Normalmente, el liderazgo recae en el gerente de cada cooperativa. Una cualidad a resaltar, al menos en esta muestra de estudio, fue el hallazgo de la ausencia de "subgrupos rivales" dentro de las cooperativas. Por otro lado en las cooperativas se da una alta cohesión grupal, hecho primordial para que se dé el éxito de la naciente empresa cooperativa. Cómo se peude observar, los resultados muestran que el estilo gerencial democrativo, prevalece en los empredimientos estudiados.

\section{Aplicación de valores cooperativos}

Los valores cooperativos se han aplicado en todas las cooperativas analizadas y en su enseñanza y divulgación ha radicado buena parte de la labor del INFOCOOP. El gráfico 7 muestra cómo se percibe su aplicación en cada una de las cooperativas incluidas en la encuesta.

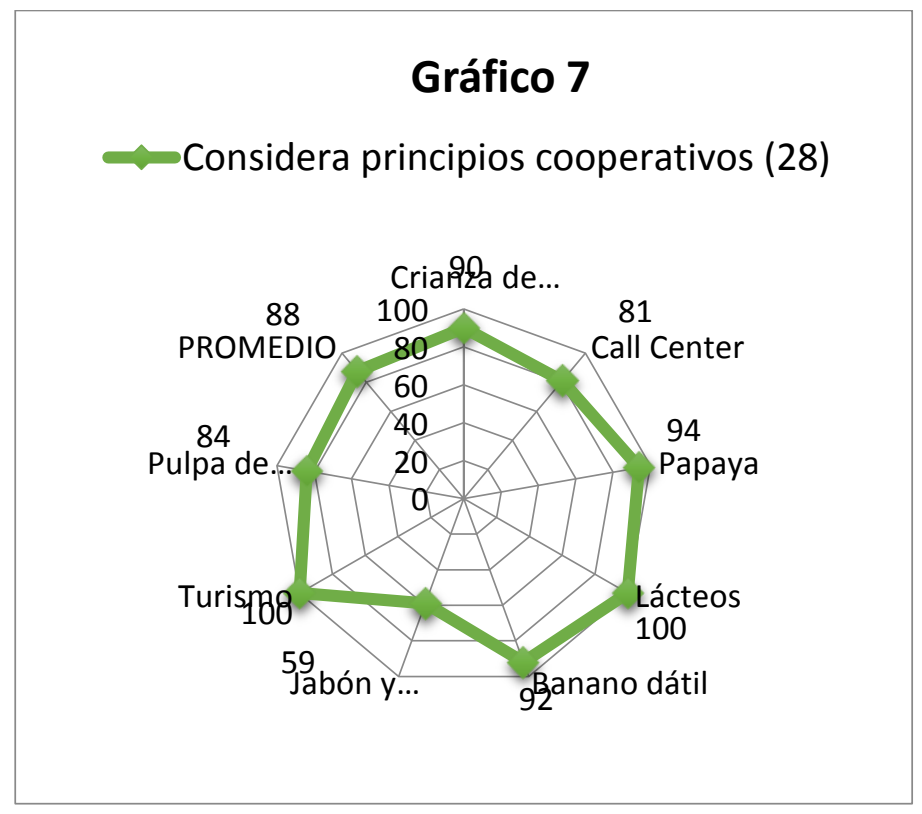

Fuente: Fedrico Li y Gustavo Hernández (2015) 
Las respuestas afirmativas del emprendimiento dedicado al jabón y champú, son las menores al constituir $59 \%$, se observa que la mayoría de las respuestan son del orden del $88 \%$ que es el promedio de respuestas afirmativas. Es importante destacar al constituirse como coperativas se da un compromiso de aplicar estos conceptos. la cooperativa de Call Center tuvo muchos problemas con muchos asociados que no comprendían que la doctrina cooperativista se separa de la mercantil en muchos aspectos, lo que implica acoger las normas y procedimientos cooperativistas o de lo contrario renunciar como asociados. En esa cooperativa hubo que aceptar la renuncia a más de 50 asociados que tenían otras aspiraciones laborales.

\section{Conclusiones}

Las diferentes cooperativas estudiadas tienen en común factores que contribuyeron a la creación, los siguientes son los hallazgos principales:

- Sus asociados habitan en zonas de pobreza, y en su mayoría están sin trabajo, o están empleados en condiciones de informalidad.

- No cuentan con infraestructura adecuada para el desarrollo de su actividad o servicio productivo.

- Los emprenimientos se ubican a distancias considerables de los centros de mayor población y principalmente de la Gran Área Metropolitana (GAM).

- Los caminos de comunicación (inraestructura) por lo general están deteriorados.

- Sus asociados tienen bajas competencias laborales. Estos factores han influenciado a que las personas se constituyan en una empresa cooperativa como una vía para salir de la pobreza.

Estos emprendimientos cooperativos tienen desventajas específicas en lo relativo a que por lo general surgen de zonas deprimidas económica y socialmente; en las cuales hay pocas oportunidades de empleo público y privado. Además, sus bajos niveles de capacitación y educación no los hace personas atractivas para darles un empleo digno y decente. (Li, 2009 a, 2009 b, 2010, 2013); (Hernandez, 2015)

Por otro lado, sus emprendimiento cooperativos se desarrollan en terrenos inadecuados y de baja productividad, aunado a esto, coincide un escaso capital (maquinaria y equipo) y ahorros, siendo que por lo general tienen bajo acceso a crédito público o privado (INEC, 2014), (Li, 2010, 2013)

En general, se puede decir que la creación de estos emprendimientos cooperativos es consecuencia de:

- Actos "detonantes" por líderes comunales.

- Por coincidencia de espacio y tiempo.

- Del resultado de estudios y acompañamientos de especialistas o estudiantes universitarios. Los resultados como se ha citado a la fecha son diversos: algunos pocos en proceso de consolidación, y otros de disolución.

Estas características se pueden visualizar a continuación:

1. Factores comunes en orígenes de cooperativas

1.1. Requerimientos de empleo e ingresos

1.1.1. Pobreza generalizada

1.1.2. Desempleo alto

1.1.3. Informalidad: necesidad de crear emprendimiento productivo

1.1.4. Mala infraestructura

1.1.5. Distancias grandes y malos caminos

1.1.6. Recurso humano con bajas calificaciones.

1.2. Desventajas específicas.

1.2.1. Los emprendimientos surgen en zonas deprimidas.

1.2.2. Pocas oportunidades de empleo público y privado.

1.2.3. Bajos niveles de capacitación

1.2.4. Terrenos inadecuados y de baja productividad.

1.2.5. Escaso capital (maquinaria y equipo) y ahorros

1.2.6. Bajo acceso a crédito

1.3. Detonantes de la creación de cooperativas:

Iniciativa de líderes comunales o "chispazos":

1.3.1. Papaya

1.3.2. Call Center

1.3.3. Pilpa de papaya

1.3.4. Banano dátil

1.3.5. jabón y champú

1.4. Coincidencia en espacio y tiempo:

1.4.1. Call Center

1.4.2. Crianza de pollo

1.4.3. Turismo 
1.5. Capacitación por especialista:

\subsubsection{Call Center}

\subsubsection{Lácteos}

Las cooperativas estudiadas presentan un líder y un sublíder; entre sus integrantes existe una relación armoniosa. No se encontró líderes negativos o personas que no estuvieran de acuerdo con los demás, al menos en la idea de salir avante (mejorar la calidad ed vida) por medio del cooperativismo.

El liderazgo generalizado de estas cooperativas es democrático y casi siempre por consenso. Se da un liderazgo transformacional, en la cual se consulta a una o dos personas de la cooperativa; curiosamente el liderazgo esta recargado en la persona del gerente de la cooperativa y no en la persona que representa presidencia de la cooperativa. Es vital que el líder tenga claridad sobre el modelo cooperativista en relación al liderazgo transformacional, el cual se entiende, como aquel que oriente, guie, motive, y empodere a las diferentes personas de la cooperativa. Muy importante de citar es que el líder tenga claridad de lo que es una empresa cooperativa y hacia donde desean ir y donde debiera estar. Es decir, con claridad de metas. (Li, 2013)

Se encontró que el factor común y aglutinador es el modelo cooperativo desde la perspectiva de su filosofía y principios cooperativos teniendo como eje y fin el ser humano, la eficiencia y eficacia como un medio de mejorar las situaciones socioeconómicas de sus integrantes (asociados).

Relacionado con el modelo cooperativo, las personas de las diferentes cooperativas estudiadas externaron que, el INFOCOOP los asiste desde inicios en que tuvieron la idea pre cooperativa a fin de poder crear y consolidar cada cooperativa; con ello se encontró que dicha institución:

$\checkmark$ Brinda apoyo desde constitución.

$\checkmark$ Capacita en temas diversos

$\checkmark$ Asesora en diversas áreas

$\checkmark$ Financia dependiendo de su capital social (x11).

Además, el ser un emprendimiento cooperativo implica apoyo estatal del gobierno, INA, universidades, fundaciones sin fines de lucro, organismos internacionales, donantes, entre otros. Siendo esto otro factor de éxito y detonante para la constitución de la cooperativa de al menos en esta muestra (Etcheverry, 2014).
Como contrapartida, se halló que estas cooperativas al estar conformada por personas con bajas competencias empresariales, aunado a la escasa o inexistente experiencia empresarial, su rentabilidad se ve cuestionada. Es así que sus decisiones se sustenten en la ausencia o baja confiabilidad de estudios de pre factibilidad o de mercado.

Por otro lado, las ventajas comparativas son muy cuestionables desde el inicio:

La cooperativa de crianza de pollo y de pulpa de papaya, con los mismos recursos, producen menos o se gastaron su capital social entrado en un impase productivo y con una eminente fuga de asociados.

A pesar de las debilidades encontratadas, estos emprendimientos, se conformaron en cooperativas por las ventajas que da el medio costarricense a saber:

- Leyes cooperativas otorgan beneficios en capacitación y financiamiento.

- Capacitación abundante proveniente de instituciones estatales y fundaciones.

- Cooperativas fomentan trabajo en equipo y cooperación, no obstante, a veces confunden a "asociados" con poca capacitación, los cuales desde su ignorancia empresarial se confunden en la toma de decisiones.

\section{Referencias}

Byrne, B. (2011). Structural Equation Modeling with Mplus. New York: Routledge.

Drucker, P. (2004). "What makes an Effective Executive". En Harvar Business Review; JulyAugust. EE.UU.

Etcheverry, R. (2014). Empresas binacionales argentino-brasileras: un nuevo instrumento de integración. Recuperado: http://www.juridicas.unam.mx/publica/librev/rev/rev dpriv/cont/8/dtr/dtr3.pdf (5 de setiembre de 2014).

Griffin, R. (2011). Administración. México: Cengage Learning.

Hernández, G. (2013). Gestión de calidad en las empresas turísticas sostenibles. Costa Rica: EUNED.

Hernández, G. (2014). "Reflexiones sobre los trabajadores transfronterizos y de temporada: análisis del "Informe metodológico del Banco Central de 
Costa Rica: trabajadores transfronterizos y de temporada en Costa Rica 2011-2012”. En Revista Nacional de Administración. Vol. 5 (2), 27-40, JulioDiciembre. UNED-Costa Rica.

Hernández, G. (2015). “Capítulo 1. Globalización y desempleo" En la sección Las cooperativas de trabajo y su impacto en el desarrollo socioeconómico costarricense; del libro: Las cooperativas de trabajo en América Latina. Argentina: Ediciones DelRevés.

Hernández, G., Li, F., Cordero A. (2016). "Factores descriptivos para la conformación de cooperativas binacionales: Costa Rica-Panamá". En Revista Nacional de Administración. Vol. 7 (1), 33 46, Enero-Junio. UNED-Costa Rica.

Hernández, R., Fernández, C. y Baptista, P. (2012). Metodología de la Investigación. Colombia: McGraw-Hill.

Hillier, F., Hillier, M. (2008). Métodos cuantitativos para la administración. México: McGrawHill.

INEC (2014). Encuesta Nacional de Hogares. Costa Rica: INEC.

Infante, I. (2012). "Corredor Mesoamericano de Integración. Integrando Mesoamérica por el Pacífico". En Revista Instituto para la Integración de América Latina y el Caribe. N. ${ }^{0}$ 34, año 16, EneroJunio.

INFOCOOP. (2014). Estadísticas. Costa Rica: INFOCOOP.

Kline, R. (1998). Principles and Practice of Structural Equation Modeling. New York: The Guilford Press.

Li, F. (1989). "Diagnóstico y propuesta de un sistema de información y control gerencial para FEDECREDITO R.L." Tesina para optar por el Bachillerato en Cooperativas y Asociativas. San José: UNED.

Li, F. (2009 a).“Cooperativismo y asociativas en la democratización de la propiedad productiva y su contribución al empleo Jornadas de trabajo, "Integración y Cooperación en América Latina.
Efectos para el mercado de trabajo y la distribución de la renta" Universidad Santiago de Compostela, Galicia, España.

Li, F. (2009 b). "EMPRENDEDURISMO JUVENIL: UNA OPCIÓN A LA CRISIS" "Sector de la economia laboral ante la crisis del desempleo global", UNED; San José. La democratización de la propiedad productiva y su contribución al empleo de las empresas cooperativas y asociativas: caso COSTA RICA Jornadas sobre Cooperativismo, Asociativas y Economía solidaría. Herramientas y metodología para su desarrollo", Universidad de la Republica. Montevideo, Uruguay.

Li, F. (2010). "Los emprendimientos colectivos de la univesidad estatal a distancia: programa jovenes empresarios" El emprendimiento colectivo y la cohesión social. Universidad de Granada, España.

Li, F. (2013 a). "El cooperativismo costarricense: Un factor de desarrollo del país desde la sustentabilidad social y empoderamiento de la propiedad productiva de los habitantes". UNISINOSBrasil

Li, F. $(2013$ b). Modelo cooperativo costarricense. Costa Rica: EUNED.

Ministerio de Planificación Nacional y Política Económica. (2014). Plan Nacional de Desarrollo (2015-2018) “Alberto Cañas Escalante”. Costa Rica: MIDEPLAN.

Porter, M. (2009). Estrategia competitiva: técnicas para el análisis de la empresa y sus competidores. México: Ediciones Pirámide 
